\title{
Are TIPS tops in the treatment of portal hypertension? A review on the use and misuse of transjugular intrahepatic portosystemic shunts
}

\author{
Richard K Sterling MD FACP, Arun J Sanyal MBBS MD FACP
}

RK Sterling, AJ Sanyal. Are TIPS tops in the treatment of portal hypertension? A review on the use and misuse of transjugular intrahepatic portosystemic shunts. Can J Gastroenterol 2000;14(Suppl D):122D-128D. Complications of portal hypertension are the Achilles heel of end-stage liver disease. Although initially developed in the 1960s, transjugular intrahepatic portosystemic shunts (TIPS) have recently gained popularity for decompressing the portal vein in patients with portal hypertension. The main indications for TIPS are the treatment of variceal hemorrhage unresponsive to endoscopic treatment and refractory ascites. Although several other applications for TIPS have been reported, they have not been tested in controlled trials. TIPS are not appropriate as initial therapy for variceal hemorrhage and ascites. Due to the virtually universal development of TIPS stenosis in the majority of patients, careful monitoring of stent patency is required. Several complications of TIPS are recognized, some of which are potentially fatal. Consequently, careful patient selection for TIPS is of paramount importance. Until further clinical trials become available, TIPS should be considered as a therapeutic option for the treatment of refractory variceal hemorrhage and refractory ascites in selected patients.

Key Words: Ascites; Portal hypertension; Transjugular intrahepatic portosystemic shunts; Variceal hemorrhage

\section{Les shunts portosystémiques transjugulaires intrahépatiques conviennent-ils au traitement de l'hypertension portale? Revue de leur utilisation à bon ou à mauvais escient.}

\begin{abstract}
RÉSUMÉ : Les complications de l'hypertension portale sont le talon d'Achille de l'insuffisance hépatique terminale. Bien que mis au point dès les années 1960, les shunts portosystémiques transjugulaires intrahépatiques (SPTI) ont récemment gagné en popularité pour la décompression de la veine porte chez les patients qui souffrent d'hypertension portale. Les principales indications des SPTI sont le traitement de l'hémorragie variqueuse qui ne répond pas aux manœuvres endoscopiques et l'ascite rebelle. Bien que plusieurs autres applications des SPTI aient été signalées, elles n'ont pas fait l'objet d'essais contrôlés. Les SPTI ne conviennent pas d'emblée aux hémorragies variqueuses et à l'ascite. En raison de leur sténose quasiinévitable chez la majorité des patients, il faut surveiller étroitement la perméabilité des SPTI. Plusieurs complications des SPTI sont connues; certaines sont fatales. Par conséquent il faut sans contredit procéder à une sélection attentive des patients candidats à un SPTI. Tant qu'on ne disposera pas d'autres essais cliniques, les SPTI doivent être envisagés comme option thérapeutique pour le traitement des hémorragies variqueuses et de l'ascite rebelles, chez des patients triés sur le volet.
\end{abstract}

This mini-review was prepared from a presentation made at the 1998 Bockus International Society of Gastroenterology Meeting, Graz, Austria, August 31 to September 3, 1998

Division of Gastroenterology, Section of Hepatology, Medical College of Virginia of Virginia Commonwealth University, Richmond, Virginia Correspondence and reprints: Dr RK Sterling, Assistant Professor of Medicine, Section of Hepatology, Medical College of Virginia, MCV Box 980341, Richmond, Virginia 23298-0341, USA. Telephone 804-828-4060, fax 804-828-4945, e-mail rksterli@hsc.vcu.edu

Received for publication February 12, 1999. Accepted February 19, 1999 


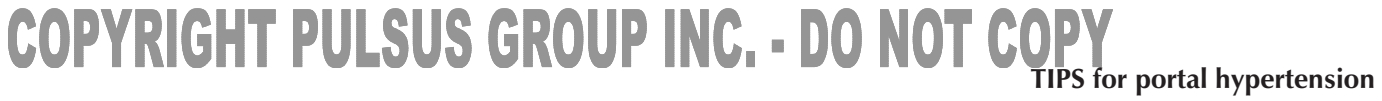

C omplications from portal hypertension are the major cause of morbidity and mortality in patients with end-stage liver disease. Treatment of recurrent portal hypertensive bleeding or refractory ascites has been limited to surgical shunts to decompress the portal system. Transjugular intrahepatic portosystemic shunts (TIPS) are a major addition to the therapeutic armamentarium against portal hypertension. TIPS are created by making an intrahepatic tract between the hepatic and portal vein using angiographic techniques via a transjugular approach, resulting in a lowresistance, side to side portosystemic shunt. TIPS do not need to be created under general anesthesia nor do they require major surgery and, therefore, have become popular in clinical practice. However, the expanding use of TIPS has also led to its misuse in some circumstances, sometimes with dire consequences for the patient. The present article reviews the accepted indications and contraindications for TIPS, the spectrum of complications associated with TIPS and the natural history of portal hypertension following the creation of TIPS.

\section{CLINICAL APPLICATIONS FOR TIPS}

TIPS are primarily used to treat the principal consequences of portal hypertension - variceal hemorrhage and ascites (Table 1). Approximately one-third of patients with varices experience active variceal hemorrhage. Bleeding is often severe and, in approximately $25 \%$ of patients, may rapidly lead to exsanguination without specific intervention (1). Those with Child class $C$ cirrhosis and actively spurting varices are most likely to continue to bleed despite therapy, with at least $50 \%$ requiring additional urgent life-saving intervention to stop the hemorrhage (2). After the bleeding is stopped, if left untreated, hemorrhage recurs in more than $70 \%$ of individuals (3). This risk is greatest in the first $48 \mathrm{~h}$ after the initial bleeding stops and gradually subsides thereafter over the next six weeks (4). Patients aged 60 years or older with large varices, renal failure and severe initial bleeding defined by a hemoglobin concentration of less than $8 \mathrm{~g} / \mathrm{dL}$ at admission are particularly at risk for early rebleeding. All deaths that occur within six weeks of an episode of active hemorrhage are considered to be bleeding-related deaths (5). Causes of early mortality include severe initial hemorrhage, recurrent bleeding, progressive liver failure and hepatic encephalopathy despite cessation of bleeding, and complications of the bleed such as infections, aspiration pneumonia and renal failure.

The goals of treatment of active variceal hemorrhage are to stop initial bleeding quickly, prevent recurrent bleeding and bleeding-related complications, and minimize treatment-associated morbidity and mortality. Endoscopic sclerotherapy or band ligation can be performed at the bedside, achieve hemostasis in $80 \%$ to $90 \%$ of subjects (6-8), decrease early rebleeding and improve short term survival. Pharmacological treatment is equally (9) or somewhat less effective (7) but more widely available and can be started in the emergency room. Consequently, endoscopic and/or pharmacological treatment are considered first-line therapy for

\author{
TABLE 1 \\ Clinical applications for transjugular intrahepatic \\ portosystemic shunts \\ Accepted indications (established in controlled trials) \\ Active variceal hemorrhage despite emergency endoscopic and/or \\ pharmacological treatment \\ Recurrent variceal hemorrhage despite adequate endoscopic \\ treatment \\ Potential indications (efficacy proven but not adequately compared \\ with that of existing therapies) \\ Bleeding isolated gastric fundic varicies \\ Refractory ascites \\ Experimental indications (efficacy not established in large scale trials) \\ Bleeding portal gastropathy \\ Budd-Chiari syndrome \\ Veno-occlusive disease \\ Hepatorenal syndrome \\ Hepatic hydrothorax \\ Bleeding ectopic varices \\ Protein-losing enteropathy due to portal hypertension
}

active variceal hemorrhage. The creation of TIPS involves moving an unstable patient to the angiography suite and often cannot be done immediately. Moreover, it is associated with a long list of complications (10). Therefore, TIPS cannot be considered first-line treatment of active variceal hemorrhage from esophageal varices.

Approximately $10 \%$ to $20 \%$ of patients fail to stop bleeding with endoscopic and/or pharmacological treatment $(6-8,11)$. Some patients rebleed in the first few days after the index bleed stops. A second attempt to control hemorrhage with endoscopic treatment is sometimes effective and is often recommended (12). However, if two attempts to control active hemorrhage fail, the risk of mortality rises exponentially (13-15). It is important to differentiate failure of endoscopic treatment for variceal hemorrhage from complications of endoscopic therapy (ie, sclerotherapy-induced ulcers) with respect to rebleeding because further treatment options may differ. We consider the recurrence of variceal hemorrhage, despite at least two sessions of endoscopic treatment performed no more than two weeks apart, to be failure of endoscopic treatment. While emergency surgery is extremely effective in stopping hemorrhage and preventing rebleeding, it is associated with a mortality rate of approximately $50 \%(13,16,17)$ due to liver failure and complications of surgery, despite achievement of effective hemostasis. Patients with severe hemorrhage, tense ascites, deep coma, aspiration pneumonia, renal failure or sepsis are at highest risk (greater than 90\%) of dying after emergency surgery $(16,18)$. Therefore, it has been recommended that such patients should not undergo operation (16).

In initial uncontrolled studies $(19,20)$, TIPS was shown to stop effectively variceal hemorrhage that was refractory to endoscopic treatment. One study focused on the role of TIPS in patients who were actively bleeding and who were consid- 


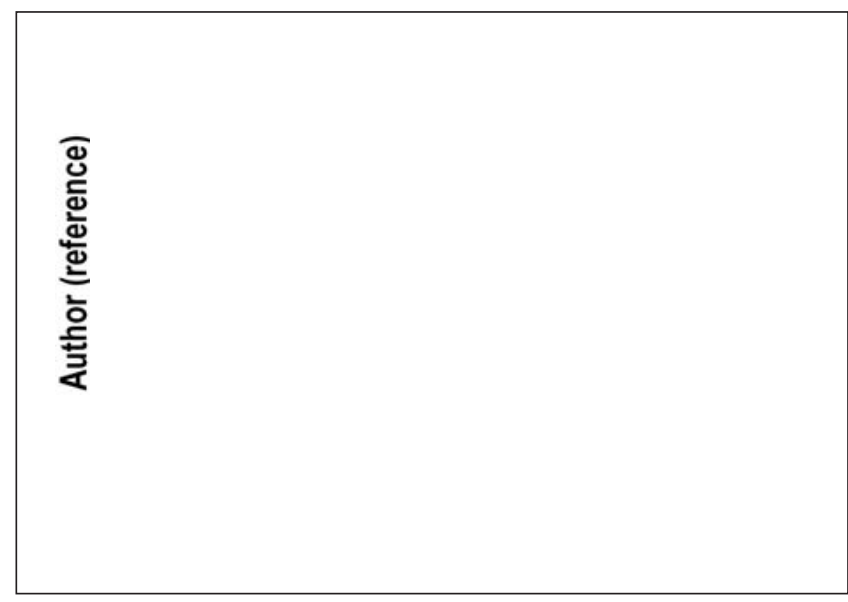

Figure 1) Comparison of transjugular intrahepatic portosystemic shunts (TIPS) and endoscopic sclerotherapy (EST) for the prevention of recurrent variceal hemorrhage. Effect on rebleeding

ered to be at high risk of dying after emergency surgery (21). In this trial of a subset of patients with an expected survival of approximately $10 \%$ (18), TIPS were successfully placed in 29 of 30 patients, and hemostasis was achieved in all patients, with a six-week rate of survival of $60 \%$ (21). In those without pulmonary aspiration, a survival rate of $90 \%$ was obtained at six weeks. These data have been corroborated by other investigators (22-25). Consequently, careful attention should be given to airway protection, with elective intubation. Unfortunately, once multiorgan failure develops, the majority of patients die, regardless of treatment (26). Therefore, TIPS should be considered early in the treatment of patients who fail endoscopic and medical therapy before the onset of complications such as aspiration, sepsis or renal failure. Based on available data, TIPS can be recommended for uncontrolled esophageal variceal hemorrhage that is unresponsive to emergent endoscopic and/or pharmacological treatment in patients who are poor risk candidates for urgent surgery.

The role of TIPS in the management of active hemorrhage not controlled by first-line endoscopic and or pharmacological therapy in patients who are otherwise good surgical candidates (Child's class A cirrhosis and absence of complications of bleeding) is controversial. A single clinical trial comparing TIPS with small diameter prosthetic $\mathrm{H}$-graft (27) is difficult to interpret because of the high rate of rebleeding in the group who received TIPS compared with that reported in the literature. Large scale, multicentre trials are needed to answer this question. Until then, local expertise will dictate the optimal choice of therapy for these patients.

Several randomized, clinical trials comparing TIPS with endoscopic treatment for the prevention of rebleeding have been published (28-31). The individual trials are difficult to compare because of the varying patient populations, treatments and study designs. Despite this heterogeneity, rebleeding rates were reduced in patients undergoing TIPS compared with rebleeding rates in those undergoing sclerotherapy in most (29-31) but not all (28) studies (Figure 1).

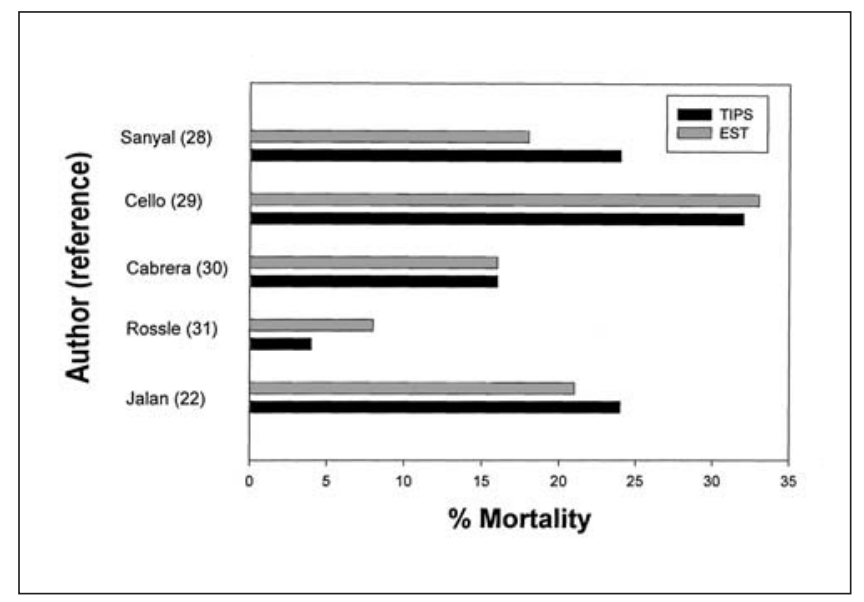

Figure 2) Comparison of transjugular intrahepatic portosystemic shunts (TIPS) and endoscopic sclerotherapy (EST) for the prevention of recurrent variceal hemorrhage. Effect on mortality

The discrepancy in the latter study is due to the relatively lower rebleeding rate in patients undergoing sclerotherapy rather than to a higher rebleeding rate in the TIPS arm (28). The superiority of TIPS for preventing rebleeding did not, however, translate into improved survival. Virtually all studies found a higher rate of mortality in patients undergoing TIPS (Figure 2). The risk of encephalopathy was also significantly higher in patients undergoing TIPS. Advanced age, liver failure, shunt diameter and history of encephalopathy before receiving TIPS were risk factors for worsening encephalopathy after receiving TIPS (32,33). Therefore, TIPS cannot be recommended as first-line therapy over endoscopic treatment for the prevention of recurrent variceal hemorrhage.

TIPS are appropriate therapy for bleeding esophageal varices in patients who fail endoscopic and/or medical management. They may be used as an alternative to surgical shunts, especially in those who are poor candidates for urgent surgery. In patients with decompensated cirrhosis who are otherwise appropriate candidates, TIPS are particularly useful as a bridge to liver transplantation.

The response of bleeding gastric varices to endoscopic treatment depends on their location. Gastric varices, in continuity with esophageal varices along the lesser curvature, respond to endoscopic therapy in the same manner as esophageal varices (34). However, patients with bleeding from gastric varices - in continuity with esophageal varices along the greater curve, or in isolation in the fundus or elsewhere in the stomach - do not respond as well to endoscopic treatment. Isolated gastric varices in the fundus of the stomach are of special interest because they are often associated with spontaneous collaterals from the splenic vein, which feeds the varices and eventually drains into the left renal vein (35). In patients with spontaneous collaterals, hemorrhage often occurs at lower portal pressures than those with esophageal varices (36).

The initial treatment of bleeding fundic varices is pharmacological. Endoscopic treatment is often ineffective and 


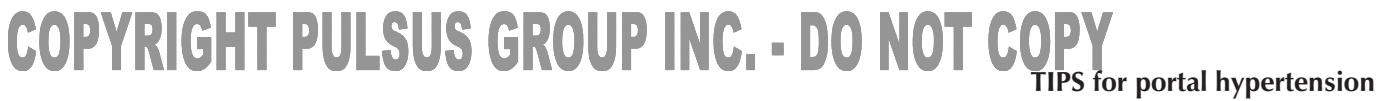

sometimes harmful. Clinical trials have shown that TIPS can effectively lower portal pressures and stop hemorrhage from bleeding gastric fundal varices $(21,24)$. However, because of spontaneous splenorenal collaterals in some patients, flow through the collateral veins and varices often persist after TIPS, even when an adequate shunt is created (35). Therefore, where surgical expertise is available, surgical ligation of the splenorenal collateral vein and portal decompression are the definitive treatments of choice. When surgical expertise is unavailable or the patient is deemed to be too ill for surgery, TIPS may provide an effective, albeit short term treatment for bleeding gastric varices.

Several caveats must be remembered to obtain the best outcomes after TIPS. Because a 'window of opportunity' exists in each patient when salvage therapy is effective, candidates for TIPS must be identified in a timely manner. Needlessly persisting with repeated endoscopic and medical attempts to stop bleeding may result in the development of sepsis, renal failure and pulmonary compromise. Once pulmonary aspiration occurs, mortality increases steeply $(21,26)$. If active bleeding continues despite medical and endoscopic therapy, balloon tamponade can be used as a temporizing measure to allow the patient to be moved to the angiography suite for TIPS placement in a relatively stable condition. Finally, while embolization of the left gastric vein is often performed along with creation of the TIPS, it is rarely necessary (21), and adds both time and expense to the procedure. Embolization is recommended if bleeding persists despite successful portal decompression by TIPS.

Ascites is the most common complication of cirrhosis (37). Its development usually heralds a progressive deterioration in the patient's condition, with a 50\% two-year survival rate (38). When ascites becomes refractory to medical management, the prognosis worsens further, and more than $50 \%$ of subjects die within six months (39). The majority of patients with mild to moderate ascites respond to sodium restriction, diuretics and occasional paracentesis. TIPS does not offer any significant advantage over standard treatment in such cases and, therefore, TIPS cannot be recommended as first-line therapy for mild to moderate ascites. When ascites becomes refractory to diuretics, the need for repeated large volume paracentesis increases. This is associated with more frequent hospitalizations, more patient discomfort, malnutrition and increased risks of other complications of cirrhosis such as spontaneous bacterial peritonitis. TIPS correct sinusoidal hypertension. Therefore, the creation of TIPS is a rational therapy for patients with refractory ascites.

Several uncontrolled series have evaluated the efficacy and safety of TIPS in patients with refractory ascites (40-45). Although these studies were not controlled and had differing definitions of refractoriness of ascites, they did show that ascites resolved or became amenable to medical management in $70 \%$ to $90 \%$ of patients after receiving TIPS. However, this improvement in ascites was offset by a failure to improve survival (41\% to $90 \%)$ and the development of severe, and sometimes crippling, encephalopathy in 35\% to $50 \%$ of patients after receiving TIPS. In two randomized, controlled trials of TIPS compared with large volume paracentesis, patients who had TIPS had either lower (46) or similar (47) rates of survival compared with patients treated medically. Therefore, TIPS appear to be effective in improving ascites in some patients who are refractory to medical management. However, because of the high rates of encephalopathy and mortality, especially in patients with advanced liver disease (Child's class C), TIPS cannot be routinely recommended as therapy for patients with refractory ascites. In patients with preserved liver function, the recommendation for TIPS must be individualized, and it must be recognized that liver failure, encephalopathy and death may develop after the procedure.

There are several caveats when using TIPS for ascites. Severe ascites pushes the liver cephalad, making the angle of the TIPS needle catheter difficult to negotiate through the hepatic vein into the liver to access the portal vein. Consequently, it is recommended that large volume paracentesis be performed on the day before the procedure (48). The relatively ascites-free state induced by paracentesis also makes it easier for the patient to lie flat for the duration of the procedure. The degree of portal decompression required to achieve an ascites-free state is controversial. Although ascites should not form if the portasystemic gradient is less than $8 \mathrm{mmHg}$ (49), it is difficult to achieve this gradient with a single stent $10 \mathrm{~mm}$ in diameter. While further decompression may be obtained by dilating the stent to $12 \mathrm{~mm}$ diameter, the benefits of a lower portosystemic gradient are offset by increasing rates and severity of encephalopathy. It is also worth noting that ascites resolved in most patients in published studies despite post-TIPS portosystemic pressure gradients of 10 to $14 \mathrm{mmHg}$. Therefore, we recommend that the initial shunt diameter not exceed $10 \mathrm{~mm}$. Finally, it is important to remember that TIPS do not correct the salt-retentive state associated with ascites development. Consequently, sodium should be restricted. The need for diuretics often decreases after creation of TIPS. Therefore, careful monitoring is required to avoid dehydration and prerenal azotemia.

TIPS have been used in the treatment of additional severe complications of portal hypertension, including portal gastropathy, Budd-Chiari syndrome, veno-occlusive disease, hepatorenal syndrome, hepatic hydrothorax, bleeding ectopic varices, portal colopathy and protein-losing enteropathy due to portal hypertension (Table 1). However, because the efficacies of these complications of portal hypertension have not been established in large scale trials, the use of TIPS remains experimental in these conditions.

Although TIPS seem attractive for the treatment for many complications of portal hypertension, they are not a panacea. Although there are isolated anecdotal reports on the use of TIPS for the treatment of pulmonary hypertension and/or hepatopulmonary syndrome, the results are not predictable. Similarly, hypersplenism and thrombocytopenia associated with portal hypertension from cirrhosis do not correct after creation of TIPS. There are no controlled data on the use of TIPS for primary prophylaxis of variceal hemorrhage, in the treatment of prehepatic portal hypertension (ie, portal vein thrombosis) or in the treatment of portal hy- 


\begin{tabular}{l} 
TABLE 2 \\
Causes of recurrent portal hypertension and bleeding after \\
transjugular intrahepatic portosystemic shunts \\
\hline Continued esophageal variceal hemorrhage \\
Stent dysfunction \\
Stenosis \\
Thrombosis \\
Retraction \\
Chinking \\
Displacement \\
Hemobilia \\
Persistent gastric varices \\
Associated with spontaneous splenorenal collaterals \\
Associated with massive splenomegaly
\end{tabular}

TABLE 3

The importance of Doppler sonography is dependent on the flow cutoff value used

\begin{tabular}{lcc}
\hline Parameter & Sensitivity & Specificity \\
\hline$<50 \mathrm{~cm} / \mathrm{s}$ & 78 & 99 \\
$<70 \mathrm{~cm} / \mathrm{s}$ & 89 & 83 \\
$<80 \mathrm{~cm} / \mathrm{s}$ & 92 & 60 \\
$<100 \mathrm{~cm} / \mathrm{s}$ & 98 & 4 \\
\hline
\end{tabular}

pertension associated with polycystic liver disease or Caroli's disease. Therefore, TIPS should not be used in these situations.

\section{COMPLICATIONS AND NATURAL HISTORY FOLLOWING CREATION OF TIPS}

The appropriate use of TIPS involves not only identification of suitable patients for the procedure, but also management after its placement. If patients are followed long enough $(34,50)$, recurrent portal hypertension occurs in most patients over time. The causes of recurrent portal hypertension (Table 2) include stenosis or thrombosis of the TIPS, stent chinking, retraction of the stent into the parenchymal tract and development of severe right-sided heart failure with reflection of systemic venous pressures into the portal tree. TIPS thrombosis occurs in up to $5 \%$ of cases and usually develops within days to weeks after placement (34). Although some advocate the use of anticoagulants routinely after creation of TIPS (51), the use of routine anticoagulation cannot be justified based on the clinical literature available.

The most important cause of recurrent portal hypertension after creation of TIPS is shunt stenosis (52), which develops in $50 \%$ to $60 \%$ of patients within six months and $70 \%$ to $90 \%$ of patients within one year. Shunt stenosis is responsible for $20 \%$ to $30 \%$ of rebleeding after creation of TIPS, and results from ingrowth of tissue from the surrounding liver into the TIPS to produce a pseudointimal lining that impinges on the shunt lumen and eventually occludes the
TABLE 4

Complications associated with transjugular intrahepatic portosystemic shunts (TIPS)

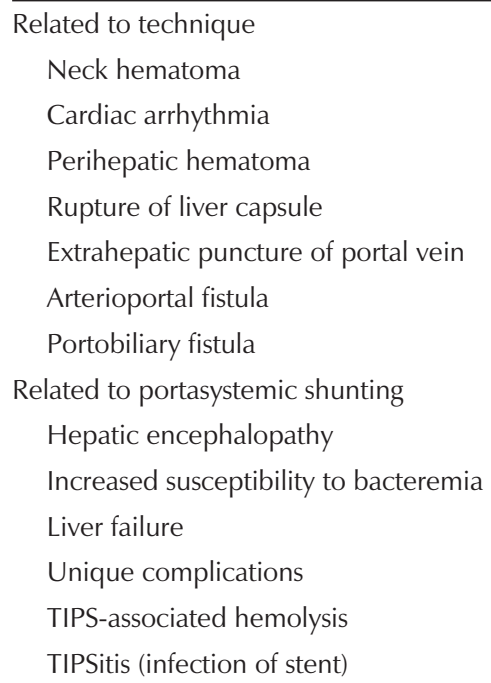

TIPS (53). It is easily treated in most cases by dilation of the stenosis, with placement of additional stents to reinforce the dilated segment $(34,50)$. While the ideal regimen for following patients with TIPS to assess shunt patency remains to be defined (54-57), two common ways include Doppler sonography performed at three- to six-month intervals and angiography at six- to 12-month intervals (34). The accuracy of Doppler sonography is dependent on several factors, including the experience of the ultrasonographer, location used for flow measurements (hepatic venous, midstent or portal vein side of the TIPS) and the cutoff value used to determine stenosis (Table 3) (58).

The correct use of TIPS also requires an appreciation of the spectrum of complications that can occur after creation of TIPS (Table 4). Complications are divided into those that are technique-related, those due to portosystemic shunting of blood away from functioning hepatocytes and unique complications that occur after creation of TIPS (10). Intraperitoneal hemorrhage is the most important and potentially fatal complication that may occur during the procedure or shortly thereafter, and results from inadvertent puncture of the liver capsule at the hepatic vein or extrahepatic puncture of the portal vein. Portosystemic encephalopathy occurs in approximately $30 \%$ of patients after creation of TIPS and is related to increasing age of the patient, shunt diameter, advanced liver failure and prior history of encephalopathy. TIPS-induced liver failure leading to death has been reported without transplantation (59). Hemolysis occurs in $10 \%$ of patients after TIPS (60). Fortunately, it is usually mild and resolves spontaneously within eight to 12 weeks. Blood is shunted away from the remaining functioning portion of the liver, a major component of the reticuloendothelial system, after creation of TIPS. As a consequence, the patients has increased susceptibility to bacterial infections (61). Finally, as with any prosthetic de- 
vice, infection of the stent (TIPSitis) has been reported (62).

\section{CONCLUSIONS}

Are TIPS tops in the treatment of portal hypertension? Current recommendations based on available clinical trials support the use of TIPS in patients who fail endoscopic and pharmacological treatment for esophageal variceal bleeding (63). Attention to airway protection and temporary stabilization by balloon tamponade can facilitate the TIPS procedure and may improve survival. TIPS are also indicated for those with recurrent variceal hemorrhage despite at least two sessions of adequate endoscopic treatment. Data are controversial on the use of TIPS in the treatment of refractory ascites. TIPS are best reserved for patients who do not have advanced liver failure. It is not known whether TIPS

\section{REFERENCES}

1. Prandi D, Rueff B, Roche-Sicot J, et al. Life-threatening hemorrhage of the digestive tract in cirrhotic patients. Am J Surg 1976,131:204-9.

2. DeFranchis R, Primignani M. Why do varices bleed? Gastroenterol Clin North Am 1992;21:85-101.

3. Graham DY, Smith JL. The course of patients after variceal hemorrhage. Gastroenterology 1981;80:800-9.

4. Smith JL, Graham DY. Variceal hemorrhage. A critical evaluation of survival analysis. Gastroenterology 1982;82:968-73.

5. D'Amico G, Morabito A, Pagliaro L. Six week prognostic indicators in upper gastrointestinal hemorrhage in cirrhotics. Front Gastrointest Res 1986;9:247-58.

6. Soderlund C, Ihre T. Endoscopic sclerotherapy vs conservative management of bleeding oesophageal varices. Acta Chir Scand 1985;151:449-56.

7. Barsoum MS,Bolous FI, El-Rooby A, Rizk-Allah MA, Ibrahim AS. Tamponade and injection sclerotherapy in the management of bleeding oesophageal varices. Br J Surg 1982;69:76-8.

8. Cello JP, Grendell JH, Crass RA, et al. Endoscopic sclerotherapy versus portacaval shunt in patients with severe cirrhosis and variceal hemorrhage. N Engl J Med 1984;311:1589-94.

9. Planas R, Quer JC, Boix J, et al. A prospective randomized trial comparing somatostatin to sclerotherapy in the treatment of acute variceal bleeding. Hepatology 1994;20:370-5.

10. Freedman AM, Sanyal AJ, Tisnado J, et al. Complications of transjugular intrahepatic portasystemic shunt (TIPS): A comprehensive review. Radiographics 1993;13:1185-210.

11. The Copenhagen Esophageal varices sclerotherapy project. Sclerotherapy after first variceal hemorrhage in cirrhotics. N Engl J Med 1984;311:1594-600.

12. Grace ND. Diagnosis and treatment of gastrointestinal bleeding secondary to portal hypertension. American College of Gastroenterology Practice Parameters Committee. Am J Gastroenterol 1997;92:1081-91.

13. Villeneuve JP, Pomier-Layrargues G, Duguay L, et al. Emergency portacaval shunt for variceal hemorrhage: a prospective study. Ann Surg 1987;206:48-52.

14. Stein C, Korula J. Variceal bleeding. What are the treatment options? Postgrad Med J 1995;98:143-9.

15. Rikkers L, Gongliang J, Burnett DA, Buchi KN, Cormier RA. Shunt surgery versus endoscopic sclerotherapy for variceal hemorrhage: late results of a randomized trial. Am J Surg 1993;165:27-33.

16. Soutter DI, Langer B, Taylor BR, Greig P. Emergency portasystemic shunting in cirrhotics with bleeding varices: a comparison of portacaval and mesocaval shunts. HPB Surg 1989;1:107-11.

17. Orloff MJ, Bell RH, Hyde PV, Skivolocki WP. Long-term results of emergency portacaval shunt for bleeding esophageal varices in unselected patients with alcoholic cirrhosis. Ann Surg 1980;192:325-39.

18. Rikkers LF, Jin G. Surgical management of acute variceal hemorrhage. World J Surg 1994;18:193-9.

19. LaBerge JM, Ring EJ, Gordon RL, et al. Creation of transjugular are better than conventional medical treatment for refractory ascites in patients with Child's class A or B cirrhosis. A large multicentre, international, randomized, prospective trial (North American Study for the Treatment of Refractory Ascites [NASTRA]) is underway to address this question. TIPS may be useful in selected patients with ectopic varices, Budd-Chiari syndrome, veno-occlusive disease or hepatorenal syndrome.

TIPS should not be used as an alternative for liver transplantation in patients with advanced hepatic decompensation (Child's class B and C). TIPS can, however, be particularly useful as a bridge to liver transplantation in selected patients with complications of portal hypertension. With careful patient selection and follow-up, TIPS will continue to play an important role in the treatment of portal hypertension.

intrahepatic portasystemic shunts with the wallstent endoprosthesis: results in 100 patients. Radiology 1993;187:413-20.

20. Rossle $\mathrm{M}$, Haag $\mathrm{k}$, Ochs $\mathrm{A}$, et al. The transjugular portosystemic stent-shunt procedure for variceal hemorrhage. $\mathrm{N}$ Engl J Med 1994;330:165-71.

21. Sanyal AJ, Freedman AM, Luketic VA, et al. Transjugular portosystemic shunts for patients with active variceal hemorrhage unresponsive to sclerotherapy. Gastroenterology 1996;111:138-46.

22. Jalan R, John TG, Redhead DN, et al. A comparative study of emergency transjugular intrahepatic portosystemic stent-shunt and esophageal transection in the management of uncontrolled variceal hemorrhage. Am J Gastroenterol 1995;90:1932-7.

23. Cao S, Monge H, Semba C, et al. Emergency transjugular intrahepatic portosystemic shunt (TIPS) in an infant: a case report. J Pediatr Surg 1997;32:125-7.

24. Chau TN, Patch D, Chan YW, et al. 'Salvage' transjugular intrahepatic portosystemic shunts: gastric fundal compared with esophageal variceal bleeding. Gastroenterology 1998;114:981-7.

25. Barange K, Rousseau H, Vinel JP. [Intrahepatic porto-systemic shunt in the treatment of hemorrhage in portal hypertension]. Presse Med 1997;26:1162-7.

26. Rubin RA, O'Brien C, Haskal ZJ, et al. Decreased survival following transjugular portosystemic shunting for Child $\mathrm{C}$ patients with high Apache II scores. Am J Gastroenterol 1995;90:556-63.

27. Rosemurgy AS, Goode SE, Zwiebel BR, Black TJ, Brady PG. A prospective trial of transjugular intrahepatic portasystemic stent shunts versus small-diameter prosthetic $\mathrm{H}$-graft portacaval shunts in the treatment of bleeding varices. Ann Surg 1996;224:378-84.

28. Sanyal AJ, Freedman AM, Luketic VA, et al. Transjugular intrahepatic portosystemic shunts compared with endoscopic sclerotherapy for the prevention of recurrent variceal hemorrhage. A randomized, controlled trial. Ann Intern Med 1997;126:849-57.

29. Cello JP, Ring EJ, Olcott EW, et al. Endoscopic sclerotherapy compared with percutaneous transjugular intrahepatic portosystemic shunt after initial sclerotherapy in patients with acute variceal hemorrhage. A randomized, controlled trial. Ann Intern Med 1997;126:858-65.

30. Cabrera J, Maynar M, Granados R, et al. Transjugular intrahepatic portosystemic shunt versus sclerotherapy in the elective treatment of variceal hemorrhage. Gastroenterology 1996;110:832-9.

31. Rossle M, Deibert P, Haag K, et al. Randomized trial of transjugular-intrahepatic-portosystemic shunt versus endoscopy plus propranolol for prevention of variceal rebleeding. Lancet 1997;349:1043-9.

32. Sanyal AJ, Freedman AM, Shiffman ML, et al. Portosystemic encephalopathy after transjugular intrahepatic portosystemic shunt: results of a prospective controlled study. Hepatology 1994;20:46-55.

33. Pomier-Layrargues G. TIPS and hepatic encephalopathy. Semin Liver Dis 1996;16:315-20.

34. Sarin SK, Lahoti D, Saxena SP, Murthi NS, Makwane UK. 
Prevalence, classification and natural history of gastric varices: long-term follow up study in 568 patients with portal hypertension. Hepatology 1992;95:434-40.

35. Sanyal AJ, Freedman AM, Luketic VA, et al. The natural history of portal hypertension after transjugular intrahepatic portasystemic shunts. Gastroenterology 1997;112:889-98.

36. Sarin SK. Diagnostic issues: portal hypertensive gastropathy and gastric varices. In: DeFranchis R, ed. Portal Hypertension II. Proceedings of the Second Baveno International Consensus Workshop on Definitions, Methodology and Therapeutic Strategies. Oxford: Blackwell Science, 1996;3:30-55.

37. Runyon B. Refractory ascites. Semin Liver Dis 1993;13:343-51.

38. Gines P, Quintero E, Arroyo V, et al. Compensated cirrhosis: natural history and prognostic factors. Hepatology 1987;7:122-8.

39. Arroyo V, Gines P, Gerbes P, et al. Definition and diagnostic criteria of refractory ascites and hepatorenal syndrome in cirrhosis. International Ascites Club. Hepatology 1996;23:164-76.

40. Quiroga J, Sangro B, Nunez M, et al. Transjugular intrahepatic portal-systemic shunt in the treatment of refractory ascites: effect on clinical renal, humoral and hemodynamic parameters. Hepatology 1995;21:986-94.

41. Somberg K, Lake JR, Tomlanovich SJ, et al. Transjugular intrahepatic portosystemic shunts for refractory ascites: assessment of clinical and humoral response and renal function. Hepatology 1995;21:709-16.

42. Wong F, Sniderman K, Liu P, et al. Transjugular intrahepatic portosystemic stent shunt: effects on hemodynamics and sodium homeostasis in cirrhosis and refractory ascites. Ann Intern Med 1995;122:816-22.

43. Ferral H, Bjarnson $\mathrm{H}$, Wegryn $\mathrm{SA}$, et al. Refractory ascites: early experience in treatment with transjugular intrahepatic portosystemic shunt. Radiology 1993;189:795-801.

44. Ochs A, Rossle M, Haag K, et al. The transjugular intrahepatic portosystemic stent-shunt procedure for refractory ascites. N Engl J Med 1995;332:1192-7.

45. Martinet JP, Fenyves D, Legault L, et al. Treatment of refractory ascites using transjugular intrahepatic portosystemic shunt (TIPS): a caution. Dig Dis Sci 1997;42:161-6.

46. Lebrec D, Giuily N, Hadengue A, et al. Transjugular intrahepatic portosystemic shunts: comparison with paracentesis in patients with cirrhosis and refractory ascites: a randomized trial. French Group of Clinicians and a Group of Biologists. J Hepatology 1996;25:135-44.

47. Ochs A, Gerbes AL, Haag K, et al. TIPS and paracentesis for the treatment of refractory ascites (RA): interim analysis of a randomized controlled trial. Hepatology 1995;25:297A. (Abst)

48. Rossle M, Haag K, Ochs A, et al. The transjugular intrahepatic portosystemic stent-shunt procedure for variceal bleeding. N Engl J Med 1994;330:165-71.

49. Wong F, Blendis L. Transjugular intrahepatic portosystemic shunt: is it the ultimate solution for refractory ascites? Hepatology 1995;22:1613-5.
50. Haskal ZJ, Pentecost MJ, Soulen MC, et al. Transjugular intrahepatic portosystemic shunt stenosis and revision: early and midterm results. Am J Radiol 1994;163:439-44.

51. Theilman L, Sauer R, Roeren T, et al. Acetylsalicylic acid in the prevention of early stenosis and occlusion of transjugular portal-systemic stent shunts: a controlled study. Hepatology 1994;20:592-7.

52. LaBerge JM, Somberg KA, Lake JR, et al. Two-year outcome following transjugular intrahepatic portosystemic shunt for variceal bleeding: results in 90 patients. Gastroenterology 1995;108:1143-51.

53. Sanyal AJ, Contos MJ, Yager D, Zhu YN, Willey A, Graham MF. Development of pseudointima and stenosis after transjugular intrahepatic portasystemic shunts: characterization of cell phenotype and function. Hepatology 1998;28:22-32.

54. Lind CD, Malisch TW, Chong WK, et al. Incidence of shunt occlusion or stenosis following transjugular intrahepatic portosystemic shunt placement. Gastroenterology 1994;106:1277-83.

55. Chong WK, Malisch TW, Mazer MJ, Lind CD, Worrell JA, Richards WO. Transjugular portosystemic shunt: US assessment with maximum flow velocity. Radiology 1993;189:789-93.

56. Foshager MC, Ferral H, Nazarran GK, Castaneda-Zuniga WR, Letourneau JG. Duplex sonography after transjugular intrahepatic portosystemic shunts (TIPS): normal hemodynamic findings and efficacy in predicting shunt patency and stenosis. Am J Radiol 1995;165:1-7.

57. Owens Ca, Bartolone C, Warner DL, et al. The inaccuracy of duplex ultrasonography in predicting patency of transjugular intrahepatic portosystemic shunts. Gastroenterology 1998;114:975-80.

58. Feldstein VA, Patel MD, LaBerge JM. Transjugular intrahepatic portosystemic shunts: accuracy of Doppler US in determination of patency and dectection of stenosis. Radiology 1996;201:141-7.

59. Rouillard SS, Bass NM, Roberts JP, et al. Severe hyperbilirubinemia after creation of transjugular intrahepatic portosystemic shunts: natural history and predictors of outcome. Ann Intern Med 1998;128:374-7.

60. Sanyal AJ, Freedman AM, Purdum PP, Shiffman ML, Luketic VA. The hematologic consequences of transjugular intrahepatic portosystemic shunts. Hepatology 1996;23:32-9.

61. Stewart C, Fratkin M, Hirsch JI, Sanyal AJ. Effects of transjugular intrahepatic portosystemic shunts (TIPS) on the function of the reticuloendothelial system (RES). Am J Gastroenterol 1997;92:269A. (Abst)

62. Sanyal AJ, Reddy KR. Vegetative infection of transjugular intrahepatic portosystemic shunts. Gastroenterology 1998;115:110-5.

63. Shiffman ML, Jeffers L, Hoofnagle JH, Tralka TS. The role of transjugular intrahepatic portosystemic shunt (TIPS) for treatment of portal hypertension and its complications. Hepatology $1995 ; 22: 1591-7$ 


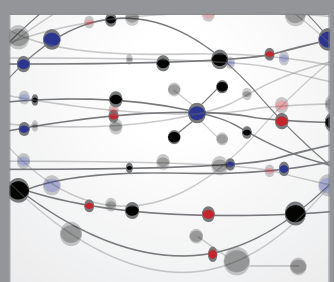

The Scientific World Journal
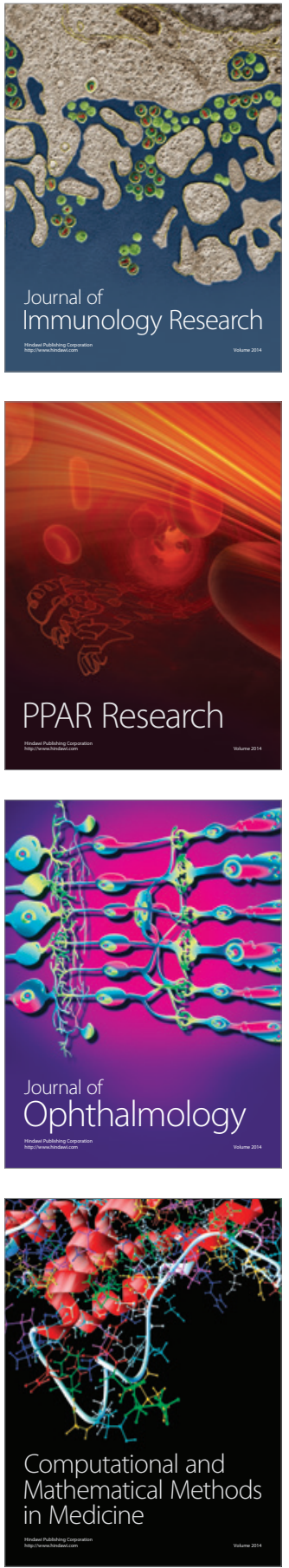

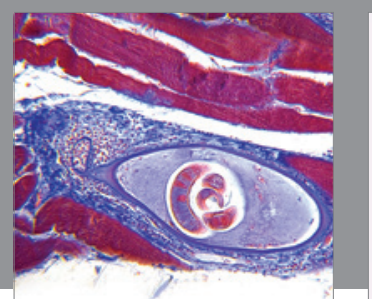

Gastroenterology Research and Practice

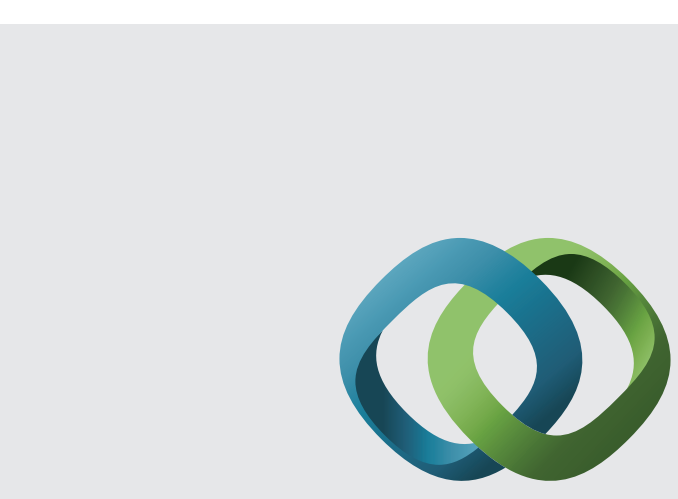

\section{Hindawi}

Submit your manuscripts at

http://www.hindawi.com
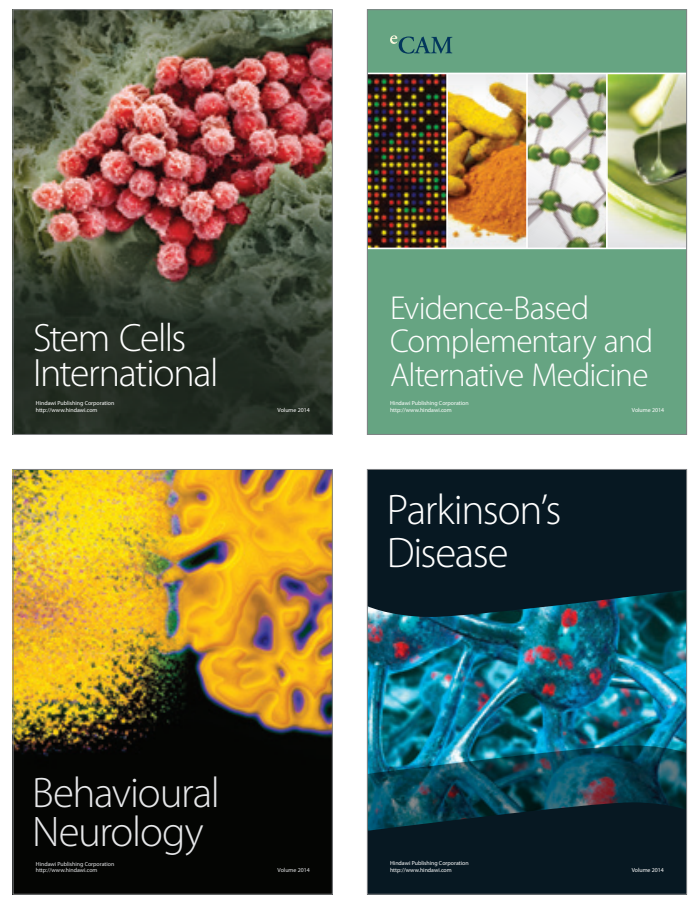
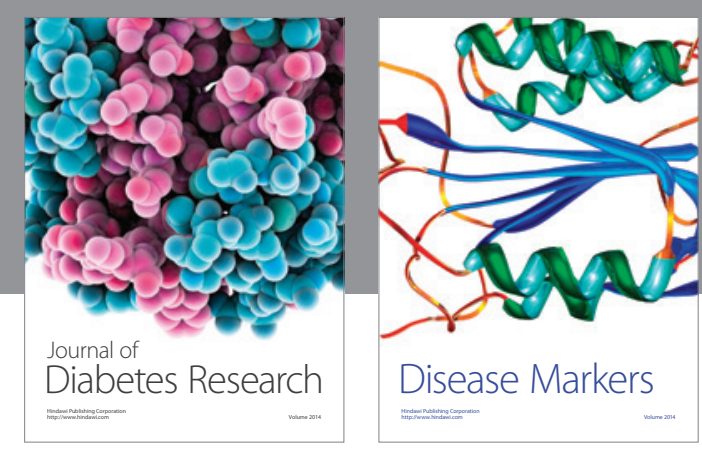

Disease Markers
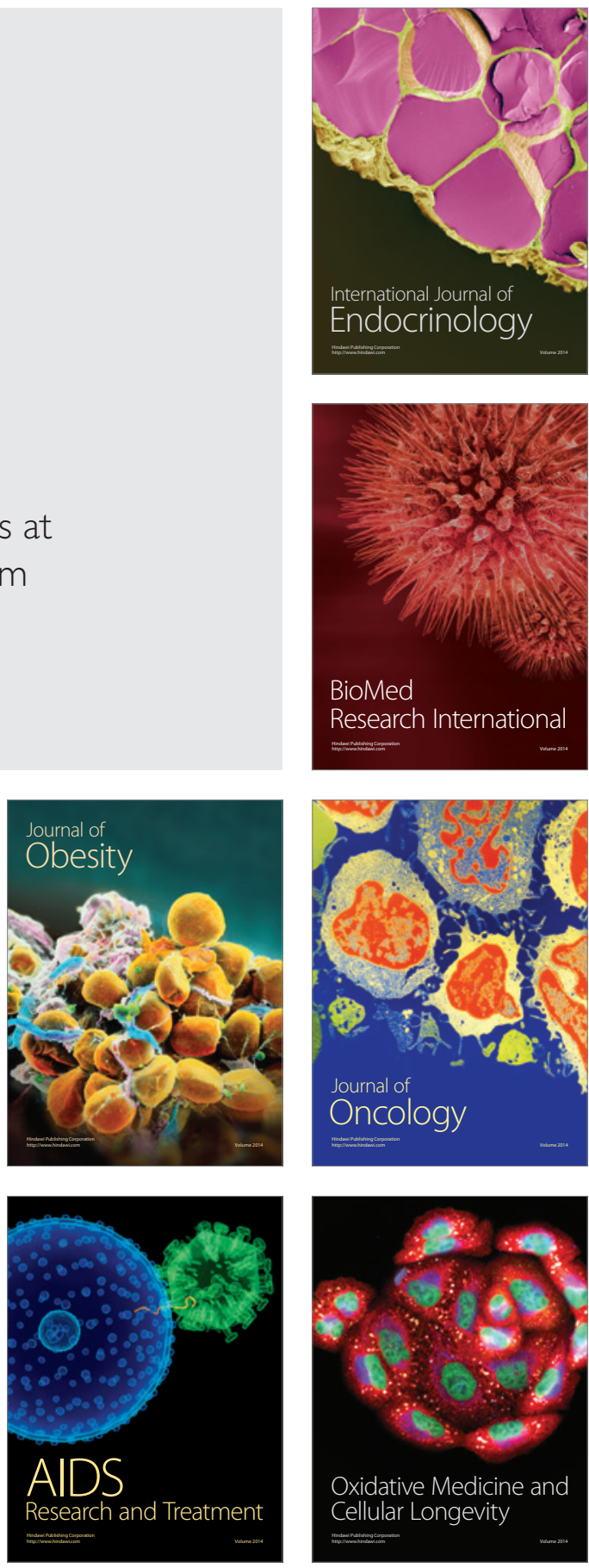